\title{
Д.С. Дубовик
}

ГОО ВПО «Донецкий национальный медицинский университет имени М. Горького», Донецк

\section{СРАВНИТЕЛЬНАЯ ОЦЕНКА ВЕГЕТАТИВНОГО ТОНУСА У ПАЦИЕНТОВ С ОЧАГОВЫМ И ДИФФУЗНЫМ РЕФЛЮКС-ГАСТРИТОМ}

Проблема изучения роли вегетативной нервной системы в патогенезе заболеваний желудочно-кишечного тракта (ЖКТ) является актуальной ввиду появления новейших научных фактов, свидетельствующих об инициирующем влиянии вегетативного дисбаланса в возникновении острых и рецидивировании хронических воспалительных гастро- и энтеропатий $[1,2]$. Однако, в настоящее время, нет четких данных в отношении оценки взаимосвязи между вегетативной дисфункцией, локальными регуляторами сократительной активности клеток мышечной оболочки желудка и особенностями морфологической картины рефлюкс-гастрита. В отношении диагностики дисфункции пилорического сфинктера у данной категории больных редко используются объективные методы, что связано со сложностью выявления и регистрации функциональных нарушений интерстициальных клеток Кахаля (ИКК) и гладких миоцитов $[12,13]$. Основная масса научной литературы базируется на данных экспериментальных исследований [13]. Очевидно, один или группа патогенетических факторов, регулируемых вегетативной нервной системой (BНC), нарушают равновесие между факторами агрессии и защиты слизистой оболочки, с одной стороны, а также факторами координации сократительной активности пилорического сфинктера, с другой стороны, что приводит к развитию гастритов.

Учитывая недостаточную изученность вегетативного статуса у больных с рефлюксгастритами, единичные исследования функционирования пилорического сфинктера в условиях измененного баланса молекулярных регуляторов активности ИКК и гладких миоцитов, имеется необходимость дальнейшего изучения этой проблемы, что и определило цель исследования.

\section{ЦЕЛЬ РАБОТЫ}

Выявить активность парасимпатического звена вегетативной регуляции у пациентов с диффузным и очаговым гастритом, обусловленных дуоденогастральным рефлюксом.

\section{МАТЕРИАЛ И МЕТОДЫ}

Основнуюгруппусоставили 164пациентов отделений гастроэнтерологии и терапии ДОКТМО (средней возраст 52,71ะ9,65 лет), у которых клинически и при фиброэзофагогастродуоденоскопии (ФЭГДС) был выявлены признаки рефлюксгастрита, обусловленного дуоденогастральным рефлюксом, отсутствовали в анамнезе операции на ЖКТ и органах гепатобилиарной зоны. На основании клинико-инструментального обследования были сформированы 1-я группа (пациенты с диффузным рефлюкс-гастритом, n=79, $48,17 \%$ случаев) и 2-я группа (пациенты с очаговым рефлюкс-гастритом, $\mathrm{n}=85,51,83 \%$ случаев). При эндоскопическом исследовании у пациентов 1-й группы регистрировали гиперемию и диффузный отек слизистой оболочки тела и антрального отдела желудка. При ФЭГДС слизистая оболочка желудка пациентов 2-й группы характеризовалась преимущественно отеком и очаговой гиперемией антрального отдела $(76,47 \%$ случаев, n=65) или сочетанием очаговой гиперемии в фундальном и антральном отделах желудка $(23,52 \%, n=20)$. Всем больным проведена ФЭГДС с помощью видеогастроскопа Pentax EG2790K. Группу сравнения составили 30 пациентов (19 женщин и 11 мужчин сходного возраста) без жалоб гастроэнтерологического профиля), не имевших патологии желудочно-кишечного тракта в анамнезе, сопоставимых по полу и возрасту с обследованными пациентами, которым была показана ФЭГДС в связи с заболеваниями, не связанными с ЖКТ. Критериями исключения в основную и контрольную группу были: прием нестероидных противовоспалительных, гормональных и цитостатических препаратов в течение последних 6 месяцев, прием антибактери-

() Д.С. Дубовик, 2021

(c) Университетская Клиника, 2021 
альных, антисекреторных препаратов в течение последнего месяца, подозрение на наличие хирургической патологии. У пациентов при ЭГДС производился забор желудочного содержимого для дальнейшего биохимического исследо-

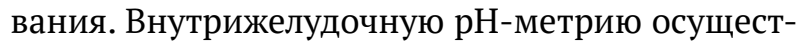
вляли микропроцессорным ацидогастрометром «АГМ-03» (АГМ-МП-03-1 фирмы НПП «ИстокСистема»). Исследование состояния надсегментарного центра гипоталамуса и корковых представительств пищевого центра включало определение вегетативного тонуса (индекс Кердо) и вегетативной реактивности путем раздражения рецепторов слизистой оболочки ротовой полости с последующим определением концентрации белков в слюне с помощью биуретового метода. Физиологическую роль гистамина и вазоактивного кишечного пептида, являющихся модуляторами парасимпатических импульсов, оценивали после путем сравнительного исследования моторной активности пилорического сфинктера у пациентов до и спустя 12 ч после однократного приема соответственно препарата «Дезал» (5 мг) и «Тримедат» (100 мг). Coстояние сегментарного отдела вегетативной регуляции оценивали по изменению диаметра антрального сфинктера при ФЭГДС в фазу сокращения и прохождения перистальтической волны, отражающего уровень его функционирования.

Статистическая обработка и анализ полученных данных проводился при помощи прикладной программы MedStat. Для проверки нормальности распределения количественных признаков использовали критерий КолмогороваСмирнова. Пороговое значение уровня статистической значимости принималось равным 0,05. В качестве описательной статистики для количественных переменных, имеющих нормальное распределение, использовались среднее значение $(\mathrm{M})$ и стандартное отклонение $(\sigma)$ в формате $\mathrm{M} \pm \sigma$. Для выявления связей между различными показателями использовался корреляционный анализ по Пирсону (с вычислением коэффициента корреляции $\mathrm{r}$ и оценкой его значимости р).

\section{РЕЗУЛЬТАТЫ И ОБСУЖДЕНИЕ}

Значения индекса Кердо у 60\% лиц контрольной группы составили 3,6ะ1,5, а у $40 \%$ были отрицательными $-5,2 \pm 2,4$, в среднем по группе -1,7, что свидетельствовало о равновесии влияний симпатического и парасимпатического отделов вегетативной нервной системы. У пациентов 1-й группы выявили изменения вегетативного тонуса, свидетельствующие о преобладании симпатикотонии (у 92\% обследованных)
- индекс Кердо составил -37,8ะ5,1 (95\% ДИ -32,4 -44,2), тогда как во 2-й группе в 96,2\% случаев доминировала парасимпатикотония (значе-

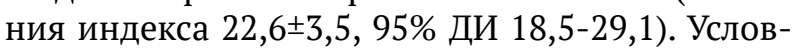
но рефлекторная оценка вегетативной реактивности позволила выявить повышение парасимпатического компонента в 1-й группе, поскольку уровень белка в слюне после условнорефлекторного теста снижался на 67,22 $\pm 3,08 \%$ по сравнению с базальным $(\mathrm{p}<0,05)$. У пациентов 2-й группы вагусные влияния не вносили значительного вклада в реактивность ВНС что проявлялось недостоверным снижением содержанием белка в слюне в ответ на стимуляцию вкусовых рецепторов на $5,79 \pm 1,30 \%$ по сравнению с базальным (против $39,45 \pm 1,84 \%$ в контроле, $\mathrm{p}>0,05)$. Данные изменения у пациентов 1-й группы можно трактовать как парасимпатикотонию в сочетании с парасимпатическим типом реактивности, что соответствует 4-му функциональному классу, а у пациентов 2-й группы как выраженную симпатикотонию с ареактивностью парасимпатического звена, [1, 11]. Сегментарные реакции в виде поддержания тонуса пилорического сфинктера у пациентов обеих групп были ослаблены, что подтверждают количественные различия изменения диаметра его внутреннего отверстия: в основной груп-

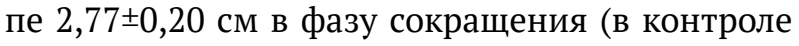
$0,31 \pm 0,10$ см) и 2,95 $\pm 0,44$ см в фазу максимального раскрытия при прохождении перистальтической волны (в контроле 1,16 $\pm 0,32$ см). В группе сравнения несостоятельность привратника проявлялась неполным смыканием его просвета $(1,90 \pm 0,25$ см) в фазу сокращения и дилатацией просвета $(3,38 \pm 0,61$ см) в фазу максимального раскрытия при прохождении перистальтической волны. Отсутствие реактивности парасимпатического звена вегетативной реактивности у пациентов 2-й группы тесно коррелировало с отсутствием тонуса пилорического сфинктера (r=0,717), что подтверждает гипотезу о роли вегетативной иннервации в патогенезе нарушений функции пилорического сфинктера.

Влияние парасимпатического нерва на моторную активность зависит от базального тонуса гладкомышечных органов и взаимодействия между эффекторными тормозными и стимуляторными нервными влияниями интрамуральных нейронов [10]. Среди преганглионарных нервных волокон кроме ацетилхолина найдены другие медиаторы - норэпинефрин, дофамин, серотонин и оксид азота. Постганглионарные тормозные нейроны освобождают аденозинтрифосфорную кислоту, вазоинтестинальный пептид (ВИП) и оксид азота, тогда как возбуждающие нейроны - серотонин и субстанцию Р. 
Однако, следует учесть, что в функциональной системе регуляции моторной активности мышечной оболочки желудка выраженность эффекторных нервных влияний прямо зависит от афферентных сигналов, исходящих от рецепторов слизистой оболочки желудка, в частности, ноцицептивных. Чувствительность ноцицепторов повышается за счет серотонина и других регуляторных веществ - гистамина, нейроактивных пептидов (вещество Р и кальцитонингенсвязанный пептид), кининов, брадикинина, а также продуктов метаболизма арахидоновой кислоты (простагландинов и лейкотриенов) и цитокинов, высвобождающихся или синтезирующихся в месте повреждения слизистой оболочки желудка $[9,11]$. В связи с этим нами исследована вегетативная реактивность пилорического сфинктера в ответ на однократную фармакологическую блокаду рецепторов гистамина и вазоинтестинального пептида.

Анализ динамики изменений двигательной активности пилорического сфинктера после фармакологической блокады гистаминовых и ВИП-рецепторов позволил установить слабо выраженные реакции моторики пилорического сфинктера на ингибирование гуморальных факторов (см. табл.). Так, эффект блокады гистаминовых рецепторов у пациентов основной группы сопровождался изменением диаметра пи-

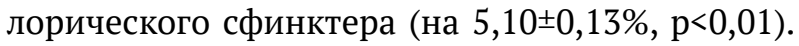
Ареактивность сфинктера отмечалась при использовании блокатора рецепторов вазоинтестинального пептида Тримедата - линейный размер пилорического сфинктера изменился лишь на $2 \%(\mathrm{p}>0,05)$. Иная картина наблюдалась во 2-й группе, где достоверно увеличился диаметр сфинктера на фоне блокировки гистамина (в 1,96 раза, $\mathrm{p}<0,001)$, что свидетельствует о его значимом влиянии на моторику гладких миоцитов посредством повышения внутриклеточного уровня цАМФ. В то же время, под влияни- ем Тримедата диаметр сфинктера уменьшился на $17,85 \pm 0,16 \%(\mathrm{p}<0,01)$.

В условиях фармакологической блокады гистаминовых рецепторов у пациентов с диффузным рефлюкс-гастритом проявилась слабо выраженная модулирующая роль данного медиатора на вегетативный тонус сфинктера, тогда как ВИП не оказывал существенного влияния на моторную активность гладких миоцитов. У пациентов с очаговым рефлюкс-гастритом гистамин оказал выраженный дилатационный эффект на фоне симпатикотонии. Блокада вазоактивного интестинального полипептида, обладающего выраженным расслабляющим действием на гладкие миоциты мышечной оболочки мышцы кровеносных сосудов, желчного пузыря, у пациентов обеих групп не оказывала значимого влияния на модуляцию вегетативного тонуса пилорического сфинктера.

Гистамин известен своим спастическим эффектом на миоциты бронхов и ЖКТ, а также инициирующим эффектом на рефлекторное ускорение моторики органов ЖКТ, опосредованным с помощью 5-НТ4-рецепторов афферентных волокон блуждающего нерва [6]. Выявленная реакция гладких миоцитов пилорического сфинктера на блокаду гистаминовых рецепторов у пациентов 2-й группы свидетельствует о взаимосвязи повышенного тонуса симпатического отдела с гистаминовой регуляцией. Данный физиологический эффект может быть опосредован подавлением высвобождения нейромедиаторов (ГАМК, ацетилхолина, серотонина, норадреналина) через Н3-рецепторы либо Н1-рецепторы [4].

ВИП является нейротрансмиттером не только ноцицепторов пищеварительной системы, но также продуцируется нейронами периферической нервной системы. Основная его локализация - в мышечных оболочке кишечника и подслизистых нейронах и нервных окончаниях ЖКТ. Клетки гладких мышц желудка и тон-

Сравнительная характеристика изменения линейных размеров пилорического сфинктера $(\Delta \mathrm{d})$ у обследованных пациентов, $\mathrm{Me}^{ \pm} \mathrm{m}$ (ДИ)

\begin{tabular}{lcc}
\hline \multicolumn{1}{c}{$\begin{array}{c}\text { Групп обследованных } \\
\text { пациентов }\end{array}$} & $\Delta \mathrm{d}$ до применения блокатора, см & $\begin{array}{c}\Delta \mathrm{d} \text { после примене- } \\
\text { ния блокатора,см }\end{array}$ \\
\hline $\begin{array}{l}\text { 1-я группа, } \\
\text { дезал (5 мг/сутки) }\end{array}$ & $0,98 \pm 0,11$ & $1,03 \pm 0,19^{*}$ \\
\hline $\begin{array}{l}\text { 1-я группа, } \\
\text { Тримедат (300 мг/сутки) }\end{array}$ & $0,98 \pm 0,11$ & $0,96 \pm 0,15$ \\
\hline $\begin{array}{l}\text { 2-я группа, } \\
\text { дезал (5 мг/сутки) }\end{array}$ & $0,28 \pm 0,01$ & $0,55 \pm 0,08^{* *}$ \\
\hline $\begin{array}{l}\text { 2-я группа, } \\
\text { Тримедат (300 мг/сутки) }\end{array}$ & $0,28 \pm 0,10$ & $0,23 \pm 0,09$ \\
\hline
\end{tabular}

Примечание: * - различия достоверны p<0,01; ** - различия достоверны p<0,05 по сравнению с показателем до фармакологической блокады. 
кой кишки экспрессируют два рецептора, которые распознают ВИП, называемые VPAC1 и VPAC2, относятся к классу В рецепторов, связанных с G-белком, также известных как семейство рецепторов секретина, которое включает рецепторы для ВИП, секретина, глюкагона, глюкагоноподобного пептида-1 и -2, кальцитонина, желудочного ингибирующего пептида и паратироидного гормона [15]. Посредством данных рецепторов ВИП способен регулировать подвижность и сократительную активность органов ЖКТ [14]. Если у пациентов 2-й группы выявленный феномен отсутствия влияния ВИП на вегетативный тонус пилорического сфинктера можно объяснить преобладанием симпатикотонии, то у пациентов 1-й группы можно предположить отсутствие холинергических влияний на продукцию данного нейротрансмиттера даже в условиях парасимпатикотонии и возможную зависимость от иных молекулярных стимулов. Действительно, эндогенный ВИП высвобождается многочисленными стимулами, такими как ацетилхолин, аденозинтрифосфорная кислота, серотонин, вещество Р и ксенин, из двух популяций ВИП-положительных нервов: холинергических и нехолинергических ВИП-высвобождающих нервов [7]. Ранее Jenkinson K.M. и Reid J.J. (2000) выявили сохранение остаточной релаксации гладких мышц дна желудка при блокаде ВИП, что позволило им предположить участие иного ингибирующего нейротрансмиттера.

\section{З АК ЛЮЧЕ Н ИЕ}

Таким образом, у пациентов с диффузным и очаговым рефлюкс-гастритом, обусловленным дуоденогастральным рефлюксом, выявили группоспецифические особенности вегетативного тонуса в виде преобладания соответственно парасимпатикотонии и симпатикотонии. Модулирующим эффектом в контроле вегетативного тонуса пилорического сфинктера обладают гистаминовые и ВИП-рецепторы, однако локализация их в функциональной системе регуляции моторной активности миоцитов пилорического сфинктера (афферентные и/или эфферетные сигналы) требует проведения дальнейших исследований.

\section{Д.С. Дубовик \\ ГОО ВПО «Донецкий национальный медицинский университет имени М. Горького», Донецк \\ СРАВНИТЕЛЬНАЯ ОЦЕНКА ВЕГЕТАТИВНОГО ТОНУСА У ПАЦИЕНТОВ С ОЧАГОВЫМ И ДИФФУЗНЫМ РЕФЛЮКС-ГАСТРИТОМ}

В работе исследовали особенности вегетативного тонуса и вегетативной реактивности у пациентов с рефлюкс-гастритом, обусловленным дуоденогастральным рефлюксом. Изменения содержания белка в слюне после условнорефлекторной стимуляции отражают баланс парасимпатического и симпатического звеньев вегетативной иннервации. Выявили различные взаимоотношения парасимпатикотонии и симпатикотонии, а также снижение модулирую- щих свойств гистамина и вазоинтестинального пептида на моторную функцию миоцитов пилорического сфинктера при диффузном и очаговом поражении слизистой оболочки желудка.

Ключевые слова: рефлюкс-гастрит, вегетативный тонус, вегетативная реактивность, рецепторы гистамина и вазоинтестинального пептида, моторика пилорического сфинктера.

\section{D.S. Dubovik}

SEI HPE «M. Gorky Donetsk National Medical University», Donetsk

\section{COMPARATIVE EVALUATION OF AUTONOMIC TONE IN PATIENTS WITH FOCAL AND DIFFUSE REFLUX GASTRITIS}

The study investigated the features of autonomic tone and autonomic reactivity in patients with reflux gastritis caused by duodenogastric reflux. Changes in the protein content in saliva after conditioned reflex stimulation reflect the balance of parasympathetic and sympathetic links of autonomic innervation. Revealed different relationships of parasympathicotonia and sympathicoto- nia, as well as a decrease in the modulating properties of histamine and vasointestinal peptide on the motor function of myocytes of the pyloric sphincter in diffuse and focal lesions of the gastric mucosa.

Key words: reflux gastritis autonomic tone, autonomic reactivity, histamine and vasointestinal peptide receptors, pyloric sphincter motility. 


\section{ЛИТЕРАТУРА}

1. Антонян В. В. Состояние вегетативного статуса и его коррекция в комплексном лечении больных эрозивноязвенными заболеваниями желудка и двенадцатиперстной кишки. Автореф. дис. д.м.н., Астрахань. 2011. 50.

2. Лычкова А.Э. Серотониновая регуляция моторной функции тонкой кишки. Экспериментальная и клиническая гастроэнтерология. 2011; 3: 130-135.

3. Лычкова А.Э. Нервная регуляция моторной активности пищевода. Экспериментальная и клиническая гастроэнтерология. 2013; 6: 52-59.

4. Blandizzi C., Tognetti M., Colucci R., Del Tacca M. Histamine $\mathrm{H} 3$ receptors mediate inhibition of noradrenaline release from intestinal sympathetic nerves. Br J Pharmacol. 2000; 129 (7): 1387-1396. doi: 10.1038/sj.bjp.0703194

5. Cruz M. T., Dezfuli G., Murphy E.C. et al. GABAB Receptor Signaling in the Dorsal Motor Nucleus of the Vagus Stimulates Gastric Motility via a Cholinergic Pathway. Front Neurosci. 2019; 13: 967.

6. Fukumoto S., Tatewaki M., Yamada T. et al. Short-chain fatty acids stimulate colonic transit via intraluminal 5-HT release in rats. Am. J. Physiol. Regul. Integr. Comp. Physiol. 2003; 284 (5): R1269-R1276.

7. Iwasaki M., Akiba Y., Kaunitz J.D. Recent advances in vasoactive intestinal peptide physiology and pathophysiology: focus on the gastrointestinal system. URL: https:// f1000research.com/articles/8-1629/v1 doi: 10.12688/ f1000research.18039.1

8. Jenkinson K.M., Reid J.J. The P2-purinoceptor antagonist suramin is a competitive antagonist at vasoactive intestinal peptide receptors in the rat gastric fundus. Br J Pharmacol. 2000; 130 (7): 1632-1638. doi: 10.1038/sj.bjp.0703482

9. Kollarik M., Ru F., Brozmanova M. Vagal afferent nerves with the properties of nociceptors. Auton Neurosci. 2010; $153(1-2): 12$.

10. Mawe G.M., Hoffman J.M. Serotonin Signaling in the Gastrointestinal Tract: Functions, dysfunctions, and therapeutic targets. Nat. Rev. Gastroenterol. Hepatol. 2013; 10 (8): 473-486.

11. Powley T. L., Hudson Ch. N., McAdams J. L. et al. Organization of Vagal Afferents in Pylorus: Mechanoreceptors Arrayed for High Sensitivity and Fine Spatial Resolution?. Auton Neurosci. 2014; 10: 36-48.

12. Rego S.L., Zakhem E., Orlando G., Bitar K. N.. Bioengineering functional human sphincteric and non-sphincteric gastrointestinal smooth muscle constructs. Methods. 2016; 99: 128-134.

13. Sanders K.M., Kito Y., Hwang S.J., Ward S.M. Regulation of Gastrointestinal Smooth Muscle Function by Interstitial Cells. Physiology (Bethesda). 2016; 31 (5): 316-326.

14. Sherwood N.M., Krueckl S.L., McRory J.E. The origin and function of the pituitary adenylate cyclase-activating polypeptide (PACAP)/glucagon superfamily. Endocr Rev. 2000; 21 (6): 619-670.

15. Teng B., Murthy K.S., Kuemmerle J.F., et al. : Selective expression of vasoactive intestinal peptide (VIP) 2/pituitary adenylate cyclase-activating polypeptide (PACAP) 3 receptors in rabbit and guinea pig gastric and tenia coli smooth muscle cells. Regul Pept. 1998; 77 (1-3): 127-134.

\section{REFERENCES}

1. Antonyan V. V. Sostoyanie vegetativnogo statusa i ego korrektsiya v kompleksnom lechenii bol'nykh erozivno-yazvennymi zabolevaniyami zheludka i dvenadtsatiperstnoi kishki. Avtoref. dis. d.m.n., Astrakhan'. 2011. 50 (in Russian).

2. Lychkova A.E. Serotoninovaya regulyatsiya motornoi funktsii tonkoi kishki. Eksperimental'naya i klinicheskaya gastroenterologiya. 2011; 3: 130-135 (in Russian).

3. Lychkova A.E. Nervnaya regulyatsiya motornoi aktivnosti pishchevoda. Eksperimental'naya i klinicheskaya gastroenterologiya. 2013; 6: 52-59 (in Russian).

4. Blandizzi C., Tognetti M., Colucci R., Del Tacca M. Histamine $\mathrm{H} 3$ receptors mediate inhibition of noradrenaline release from intestinal sympathetic nerves. Br I Pharmacol. 2000; 129 (7): 1387-1396. doi: 10.1038/sj.bjp.0703194

5. Cruz M.T., Dezfuli G., Murphy E.C. et al. GABAB Receptor Signaling in the Dorsal Motor Nucleus of the Vagus Stimulates Gastric Motility via a Cholinergic Pathway. Front Neurosci. 2019; 13: 967.

6. Fukumoto S., Tatewaki M., Yamada T. et al. Short-chain fatty acids stimulate colonic transit via intraluminal 5-HT release in rats. Am. J. Physiol. Regul. Integr. Comp. Physiol. 2003; 284 (5): R1269-R1276.

7. Iwasaki M., Akiba Y., Kaunitz J.D. Recent advances in vasoactive intestinal peptide physiology and pathophysiology: focus on the gastrointestinal system. URL: https:// f1000research.com/articles/8-1629/v1 doi: 10.12688/ f1000research.18039.1

8. Jenkinson K.M., Reid J.J. The P2-purinoceptor antagonist suramin is a competitive antagonist at vasoactive intestinal peptide receptors in the rat gastric fundus. Br J Pharmacol. 2000; 130 (7): 1632-1638. doi: 10.1038/sj.bjp.0703482

9. Kollarik M., Ru F., Brozmanova M. Vagal afferent nerves with the properties of nociceptors. Auton Neurosci. 2010; $153(1-2): 12$.

10. Mawe G.M., Hoffman J.M. Serotonin Signaling in the Gastrointestinal Tract: Functions, dysfunctions, and therapeutic targets. Nat. Rev. Gastroenterol. Hepatol. 2013; 10 (8): 473-486.

11. Powley T. L., Hudson Ch. N., McAdams J. L. et al. Organization of Vagal Afferents in Pylorus: Mechanoreceptors Arrayed for High Sensitivity and Fine Spatial Resolution?. Auton Neurosci. 2014; 10: 36-48.

12. Rego S.L., Zakhem E., Orlando G., Bitar K. N.. Bioengineering functional human sphincteric and non-sphincteric gastrointestinal smooth muscle constructs. Methods. 2016; 99: 128-134.

13. Sanders K.M., Kito Y., Hwang S.J., Ward S.M. Regulation of Gastrointestinal Smooth Muscle Function by Interstitial Cells. Physiology (Bethesda). 2016; 31 (5): 316-326.

14. Sherwood N.M., Krueckl S.L., McRory J.E. The origin and function of the pituitary adenylate cyclase-activating polypeptide (PACAP)/glucagon superfamily. Endocr Rev. 2000; 21 (6): 619-670.

15. Teng B., Murthy K.S., Kuemmerle J.F., et al. : Selective expression of vasoactive intestinal peptide (VIP) 2/pituitary adenylate cyclase-activating polypeptide (PACAP) 3 receptors in rabbit and guinea pig gastric and tenia coli smooth muscle cells. Regul Pept. 1998; 77 (1-3): 127-134. 